\title{
Kinetics study of oil extraction from Citrus auranticum L. by solvent-free microwave extraction
}

\author{
Heri Septya Kusuma*, Prilia Dwi Amelia, Cininta Admiralia, Mahfud Mahfud* \\ Department of Chemical Engineering, Institut Teknologi Sepuluh Nopember, Jalan Raya ITS, Keputih, Sukolilo, Surabaya 601 11, Indonesia
}

Article history:

Received: 21 April 2016/ Received in revised form: 6 May 2016/ Accepted: 19 May 2016

\begin{abstract}
Citrus and its oil are of high economic and medicinal value because of their multiple uses, such as in the food industry, cosmetics and folk medicine. The aim of this study is to investigate the potential of solvent-free microwave extraction for the extraction of essential oils from Citrus auranticum L. peels. Specifically, this study verifies the kinetics based on second-order model and mechanism of solvent-free microwave extraction of Citrus auranticum L. peels. Solvent-free microwave extraction is used to extract essential oils from Citrus auranticum L. peels. The initial extraction rate, the extraction capacity and the second-order extraction rate constant were calculated using the model. Using a three-step experimental design of the kinetics of oil extraction from Citrus auranticum L. peels by solvent-free microwave extraction, this study showed that the extraction process was based on the second-order extraction model. The initial extraction rate $(h)$, the extraction capacity $\left(C_{\mathrm{S}}\right)$, the second-order extraction rate constant $(k)$, and coefficient of determination $\left(R^{2}\right)$ was $0.7483 \mathrm{gL}$ $\min ^{-1}, 0.7291 \mathrm{~g} \mathrm{~L}^{-1}, 1.4075 \mathrm{~L} \mathrm{~g}^{-1} \mathrm{~min}^{-1}$ and 0.9992 , respectively.
\end{abstract}

Keywords: Citrus auranticum L.; cit rus oil; kinetic study; solvent-free microwave extraction

\section{Introduction}

Citrus fruits and their by-products are of high economic and medicinal value because of their multiple uses, such as in the food industry, cosmetics and folk medicine [1]. In addition to large scale consumption as fresh fruits, the Citrus fruits are mainly processed to produce juice. The waste of Citrus processing industry, left after juice extraction, such as peels, seeds and pulps, corresponding to about $50 \%$ of the raw processed fruit, can be used as a potential source of valuable by-products [2]. Specifically, the Citrus peels, commonly treated as agro-industrial waste, are a potential source of valuable secondary plant metabolites and es sential oils [3].

Citrus peel essential oils are reported to be one of the rich sources of bioactive compounds namely coumarins, flavonoids, carotenes, terpenes and linalool etc. [4]. Recently, Citrus peel essential oils have also been searched for their natural antioxidant and antimicrobial properties [5]. It is widely accepted that biological activities of plant materials are strongly linked with their specific chemical composition, mainly the secondary metabolites such as plant phenolics and flavonoids [6].

These substances can be extracted by different methods: hydrodistillation, extraction with organic solvent and supercritical fluid extraction (SFE) [7]. Among these methods, hydrodistillation has been the most common approach to extract the essential oils from the medicine herbs and plants

\footnotetext{
* Corresponding author. Tel.: +6285730780240
}

Email: heriseptyakusuma@gmail.com; mahfud@chem-eng.its.ac.id
[8]. Alternative methods, employing microwaves, have been developed in order to shorten extraction time, improve the extraction yield, and reduce the operational costs. Microwaveassisted procedures for isolating essential oils have become attractive for use in laboratories and industry. The advantages of using microwave energy for oil extraction are more effective heating, fast energy transfer, faster response to process heating control, faster start-up, increased production, and elimination of some process steps. Novel microwaveassisted extraction (MAE) [9] methods such as microwaveassisted hydrodistillation (MAHD) $[10,11,12,13]$ and solventfree microwave extraction (SFME) [14] have proven to be fast and efficient methods for extracting es sential oils.

However, to the best of the authors' knowledge no work has been published on the extraction of essential oil from Citrus auranticum L. peels using microwave ovens for heating. Therefore, the objective of this study was to investigate the potential of SFME for the extraction of essential oils from Citrus auranticum L. peels. In this study, the authors also attempted to know and verify the kinetics based on second-order model and mechanism of SFME of Citrus auranticum L. peels.

\section{Materials and Methods}

\subsection{Raw materials}

In this study, Citrus auranticum L. was collected from Keputran market, Surabaya, Indonesia. Orange fruits were 
peeled using a hand procedure which separates the external part of the orange, giving a yield of $\pm 20 \% \mathrm{w} / \mathrm{w}$ of orange peel with respect to the whole friut. Fresh plant material was employed in solvent-free microwave extraction. All other chemicals and solvents used were of analytical grade.

\subsection{Solvent-free microwave extraction}

In employing SFME, we used a domestic microwave oven (EMM-2007X, Electrolux, 20 1, maximum delivered power of $800 \mathrm{~W}$ ) with wave frequency of $2450 \mathrm{MHz}$. The dimensions of the PTFE-coated cavity of the microwave oven were 46.1 $\mathrm{cm} \times 28.0 \mathrm{~cm} \times 37.3 \mathrm{~cm}$. The microwave oven was modified by drilling a hole at the top. A round bottom flask with a capacity of $1000 \mathrm{ml}$ was placed inside the oven and was connected to the three-way adapter and liebig condenser through the hole. Then, the hole was closed with PTFE to prevent any loss of the heat inside.

In this method, fresh peels were placed in the microwave oven. Fourty grams of Citrus auranticum L. peels was placed inside the reaction flask and heated by microwave irradiation with $400 \mathrm{~W}$ (50\% power) for $60 \mathrm{~min}$. During the process, the vapor passed through the condenser outside the microwave cavity where it was condensed (Fig. 1). The essential oils and water was simply separated by decantation. Every $10 \mathrm{~min}$, the collected essential oils was decanted from the condensate. The essential oils were collected in amber vials, dried under anhydrous sodium sulfate and stored at $4^{\circ} \mathrm{C}$. The extraction yield of citrus oil was calculated according to the equation given:

$$
y=\frac{V}{W} \times 100
$$

where $\mathrm{y}$ is the citrus oil yield $(\%, \mathrm{w} / \mathrm{w}), \mathrm{V}$ is the weight or mass of extracted citrus oil $(\mathrm{g})$ and $\mathrm{W}$ is the weight or mass of fresh Citrus auranticum L. peels (g).

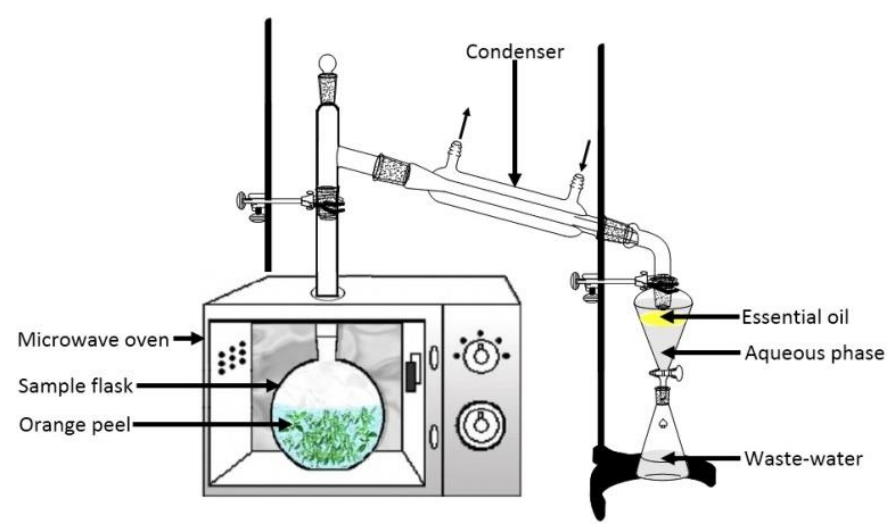

Fig. 1. Schematic representation of the solvent-free microwave extraction apparatus used in this study

\subsection{Kinetic model}

Second-order mechanism model means that the extraction occurs in two simultaneous processes. The amount of extracted oil increases rapidly with time at the beginning and then decreases slowly with the time until the end of extraction process $[15,16,17,18]$. The rate of dissolution for the essential oil contained in the solid to solution can be described by Equation (2)

$$
\frac{d C_{t}}{d t}=k\left(C_{s}-C_{t}\right)^{2}
$$

where $k$ is the second-order extraction rate constant $\left(\mathrm{L} \mathrm{g} \mathrm{g}^{-1}\right.$ $\min ^{-1}$ ), $C_{\mathrm{S}}$ the extraction capacity (concentration of essential oil at saturation in $\mathrm{g} \mathrm{L}^{-1}$ ) and $C_{t}$ is the concentration of citrus oil at any time $t(\mathrm{~min})$.

By considering the initial and boundary conditions, $t=0$ to t and $C_{t}=0$ to $C_{t}$, the integrated rate law for second-order extraction was obtained:

$$
C_{t}=\frac{C_{s}{ }^{2} k t}{1+C_{s} k t}
$$

By transforming Eq. (3), a linear form shown in Eq. (4) can be obtained and the extraction rate can be written as Eq. (5):

$$
\begin{aligned}
\frac{t}{C_{t}} & =\frac{1}{k C_{s}{ }^{2}}+\frac{t}{C_{s}} \\
\frac{C_{t}}{t} & =\frac{1}{1 /\left(k C_{s}{ }^{2}\right)+t / C_{s}}
\end{aligned}
$$

The initial extraction rate, $h$, as $C t / t$ when $t$ approaches 0 , can be defined as:

$$
h=k C_{s}^{2}
$$

and, the concentration of essential oil at any time can be expressed after rearrangement as:

$$
C_{t}=\frac{t}{1 / h+t / C_{s}}
$$

The initial extraction rate, $h$, the extraction capacity, $C_{\mathrm{S}}$, and the second-order extraction rate constant, $k$, can be determined experimentally from the slope and intercept by plotting $t / C_{t}$ versus $t$.

\section{Results and Discussion}

As shown in Fig. 2, the rate of extraction was increased as the time of extraction increased until it reached plateau or constant after 50 min of extraction. $0.65 \%$ extractable oil was obtained in the $10 \mathrm{~min}$ of extraction until it became plateau $(0.72 \%)$. The experimental result was analyzed using secondorder model by plotting $t / C_{t}$ versus time as shown in Fig. 3.

According to Fig. 2, the rate of extraction was fast at the beginning and slow until the end of the extraction process. The extraction process takes place in three different steps: an equilibrium phase where the phenomena of solubilization and partition intervene, in which the substrate is removed from the outer surface of the particle at an approximately constant velocity. Then, this stage is followed by an intermediary transition phase to diffusion. The resistance to mass transfer begins to appear in the solid-liquid interface; in this period the mass transfer by convection and diffusion prevails. In the last phase, the solute must overcome the interactions that bind it to the matrix and diffuse into the extracting solvent. The extraction rate in this period is low, characterized by the 
removal of the extract through the diffusion mechanism. This point is an irreversible step of the extraction process; it is often regarded as the limiting step of the process [19]. Diffusion rate decreased as the time of extraction increased due to the high solute concentration in liquid at the third stage. Even though the extraction time increased after the maximum citrus oil was extracted, it did not show any changes or significant in amount of oil extracted. The trend of citrus oil recovery under extraction time of $10 \mathrm{~min}, 50 \mathrm{~min}$ and $60 \mathrm{~min}$, respectively was $89.89 \%, 9.06 \%$ and $1.05 \%$.

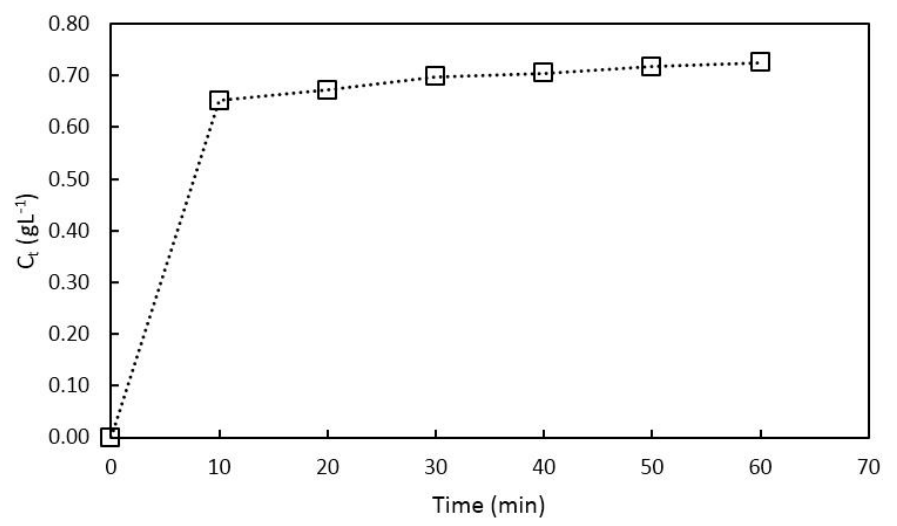

Fig. 2. The concentration of citrus oil in the solution at any time, $\mathrm{C}_{\mathrm{t}}\left(\mathrm{gL}^{-1}\right)$ versus time (min)

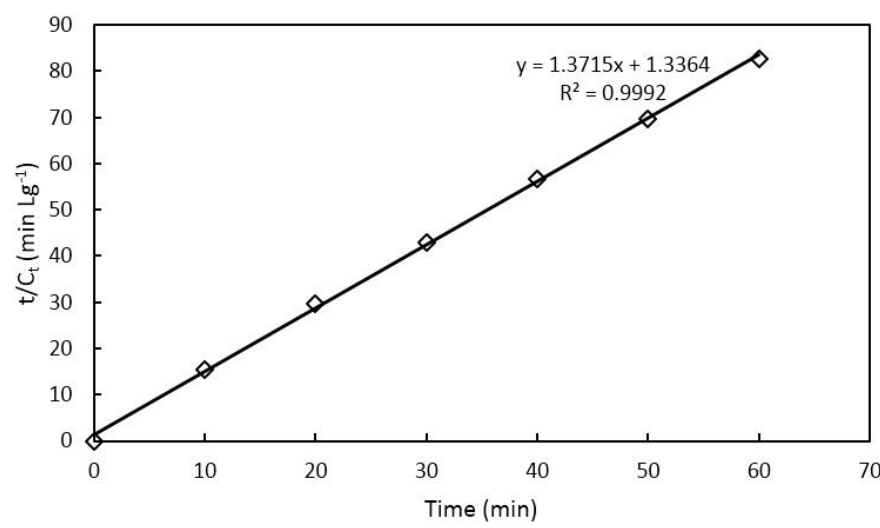

Fig. 3. Second-order extraction kinetics of citrus oil

The initial extraction rate, $h$, the extraction capacity, $C_{\mathrm{S}}$, the second-order extraction rate constant, $k$, and coefficient of determination, $R^{2}$, were calculated experimentally by referring to the linier curve in Fig. 3. From graph $t / C_{t}$ versus time, slope is equal to $1 / C_{\mathrm{S}}$, and intercept is equal to $1 / h$. The data showed in Table 1.

Table 1. Linierization of second-order kinetic model of solvent-free microwave extraction of Citrus auranticum L. peel

\begin{tabular}{llll}
\hline$C_{\mathrm{S}}\left(\mathrm{g} \mathrm{L}^{-1}\right)$ & $k\left(\mathrm{~L} \mathrm{~g}^{-1} \min ^{-1}\right)$ & $h\left(\mathrm{~g} \mathrm{~L}^{-1} \min ^{-1}\right)$ & $R^{2}$ \\
\hline 0.7291 & 1.4075 & 0.7483 & 0.9992 \\
\hline
\end{tabular}

For this study, the maximum yield oil extracted by SFME is higher compared to conventional hydrodistillation (HD). In the work of Kamal et al. (2011) [20] it was observed that citrus oil yield extracted from fresh peels by HD for 3 hours is $0.24 \pm 0.01 \%$.

Fig. 4 shows the mechanism of SFME compared to HD method. In $\mathrm{HD}$, the temperature increased often slowly, depended on the thermal conductivity and on convection currents, where the heat transfer was occurring from the outside to the inside while mass transfer was occurring from the inside to the outside of the Citrus auranticum L. peels [21].

Whereas, in SFME the cell was subjected to severe thermal stress, the temperature increased much faster than the conventional heating, depending on the effects of microwave irradiations and the internal dielectric heating of the Citrus auranticum L. peels with the action of the "in situ" water, where both the heat and mass transfers were in the same direction from the inside to the outside of the gland. As a result of internal superheating which leaded to the severe vaporization of the "in situ" water and localized a high pressure gradient inside the gland, a dramatic expansion and a rapid rupture of the cell walls were occurring. Finally, the essential oils were migrated quickly from the inside of the Citrus auranticum $\mathrm{L}$. peels to the surrounding.

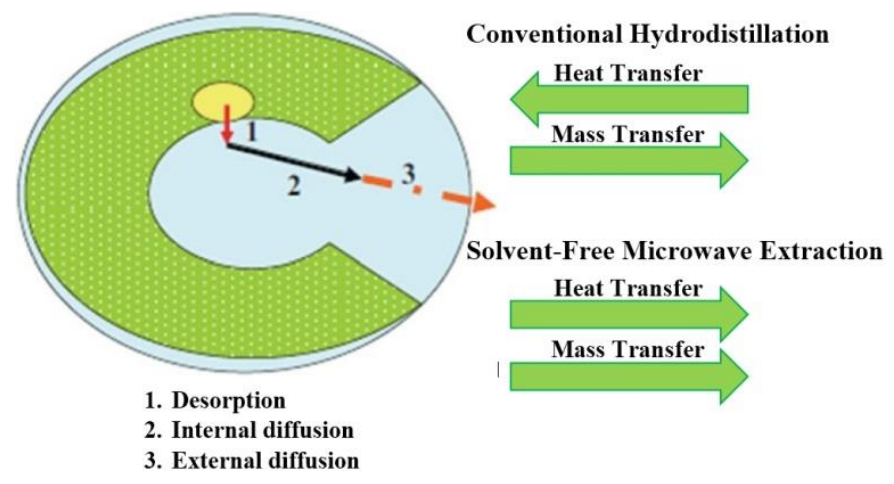

Fig. 4. Heat and mass transfer mechanisms in conventional hydrodistillation and solvent-free microwave ex traction of cit rus oil

\section{Conclusion}

The extraction yield of citrus oil obtained by SFME method for $60 \mathrm{~min}$ is $0.72 \%$. Kinetics of oil extraction from Citrus auranticum $\mathrm{L}$. peels by SFME method proved that the extraction process was based on the second-order extraction model as the experiment was conducted in three different steps. The initial extraction rate $(h)$, the extraction capacity $(C \mathrm{~S})$, the second-order extraction rate constant $(k)$, and coefficient of determination $\left(R^{2}\right)$, respectively was $0.7483 \mathrm{~g} \mathrm{~L}^{-}$ ${ }^{1} \min ^{-1}, 0.7291 \mathrm{~g} \mathrm{~L}^{-1}, 1.4075 \mathrm{~L} \mathrm{~g}^{-1} \mathrm{~min}^{-1}$ and 0.9992 .

\section{References}

1. J. Silalahi, Anticancer and health protective properties of Citrus fruit components, Asia Pac. J. Clin. Nutr. 11 (2002)79-84.

2. T. A. El-Adawy, E. H. Rehman, A. A. El-Bedawy and A. M. Gafar, Properties of some Citrus seeds. Part 3. Evaluation as a new so urce of potential oil, Nahrung 43 (1999) 385-391. 
3. V. Andrea, N. Nadia, R. M. Teresa and A. Andrea, Analysis of some Italian lemon liquors (Limoncello), J. Agric. Food Chem. 51(17)(2003) 4978-4983.

4. L. Mondello, A. Casilli, P. Q. Tranchida, P. Dugo, and G. Dugo, Comprehensive two-dimensional GC for the analysis of Citrus essen tial oils, Flavour Fragrance J. 20 (2005) 136-140.

5. G. K. Jayaprakasha, B. Girennavar and B. S. Patil,Radical scavenging activities of RioRed grapefruits and Sour orange fruit extracts in different in vitro model systems, Bioresour. Technol. 99(10) (2008) 4484-4494.

6. M. Viuda-Martos, Y. Ruiz-Navajas, J. Fernández-Lo' pez and J. Pe'rezA'lvarez, Antifungal activity of lemon (Citrus lemon L.), mandarin (Citrus reticulata L.), grapefruit (Citrus paradisi L.) and orange (Citrus sinensis L.) essential oils, Food Control 19 (12)(2008)1130-1138.

7. S. Filip, S. Vidovic, D. Adamovic and Z. Zekovic, Fractionation of nonpolar compounds of basil (Ocimum basilicum L.) by supercritical fluid extraction (SFE), J. Supercrit. Fluids 86 (2014) 85-90.

8. Chinese Pharmacopoeia Committee, Chinese Pharmacopoeia, 9th edition, China Medical Science and Technology Press, Beijing, Chin a, 2010, Appendix 62.

9. B. Kaufmann and P. Christen, Recent extraction techniques for n atural products: microwave-assisted extraction and pressurised solvent extraction, Phytochem. Anal. 13 (2002) 105-113.

10. M. T. Golmakani and K. Rezaei, Comparison of microwave- assisted hydrodistillation with the traditional hydrodistillation method in the extraction of essential oils from Thymus vulgaris L., Food Chem. 109 (2008a) 925-930.

11. M. T. Golmakani and K. Rezaei, Microwave-assisted hydrodistillation of essential oils from Zataria multiflora Boiss., Eur. J. Lipid Sci. Technol. 110 (2008b) 448-454.

12. H. W. Wang, Y. Q. Liu, S. L. Wei, Z. J. Yan and K. Lu, Comparison of microwave-assisted and conventional hydrodistillation in the extraction of essential oils from mango (Mangifera indica L.) flowers, Molecules 15 (2010) 7715-7723.

13. H. S. Kusuma and M. Mahfud, Microwave-assisted hydrodistillation for extraction of essential oil from patchouli (Pogostemoncablin) le aves, Period. Polytech., Chem. Eng. 60 (2016) 1-11.

14. A. Filly, X. Fernandez, M. Minuti, F. Visinoni, G. Cravotto and F. Chemat, Solvent-free microwave extraction of essentialoil from aromatic herbs: from laboratory to pilot and industrialscale, Food Chem. 150 (2014) 193-198.

15. Y. S. Ho, H. A. H. Oumarou, H. Fauduet and C. Porte, Kinetics and model building of leaching of water-soluble compounds of Tilia sapwood. Sep. Purif. Technol. 45 (2005) 169-173.

16. L. R. Rabesiaka, J. Havet, C. Porte,H. Fauduet, Solid-liquid extra ction of protopine from Fumaria officinalis L.-Analysis determination, kinetic reaction and model building, Sep. Purif. Technol. 54 (2007) 253-261.

17. J. T. Uhm and W. B. Yoon, Effects of high-pressure process on kin etics ofleaching oil from soybean powder using hexane in batch systems, J. Food Sci. 76 (2011) 444-449.

18. S. Meizane and H. Kadi, Kinetics and thermodynamics of oil extraction from olive cake, J. Am. Oil Chem. Soc. 85 (2008) 391-396.

19. D. E. Raynie, Extraction, In: I. D. Wilson, E. R. Adlard, M. Cooke, C. F. Poolie, (eds) Encyclopedia of separation science, Academic Press, San Diego, 2000.

20. G. M. Kamal, F. Anwar, A. I. Hussain, N. Sarri and M. Y. Ashraf, Yield and chemical composition of Citrus essential oils as affected by drying pretreatment of peels, Int. Food Res. J. 18(4) (2011) 1275-1282.

21. H. S. Kusuma and M. Mahfud, Preliminary Study: Kinetics of Oil Extraction from Sandalwood by Microwave-assisted Hydrodistillation. ASEAN J. Chem. Eng. 15(2) (2015) 62-69. 